\title{
Effect of storage time of transfused plasma on early and late mortality after coronary artery bypass grafting
}

\author{
Albert H. M. van Straten, MD, ${ }^{a}$ Mohamed A. Soliman Hamad, MD, ${ }^{a}$ Elisabeth J. Martens, PhD, \\ M. Erwin S. H. Tan, MD, PhD, ${ }^{\mathrm{a}}$ Andre M. de Wolf, MD, ${ }^{\mathrm{d}}$ Volkher Scharnhorst, $\mathrm{PhD},{ }^{\mathrm{c}}$ and \\ André A. J. van Zundert, MD, PhD, FRCA $^{\mathrm{e}}$
}

Objectives: Because some concern has been raised about the storage time of red blood cells and outcomes after
cardiac surgery, we investigated whether longer storage time of transfused plasma increases the risk for early or
late mortality among patients who have undergone coronary artery bypass grafting.

Methods: We retrospectively analyzed the data of all 10,626 patients who underwent isolated coronary artery bypass grafting in Catharina Hospital, Eindhoven, The Netherlands, between January 1998 and December 2007. All patients who received at least 1 unit of plasma intraoperatively or during the first 5 postoperative days were studied. They were divided into 3 groups (only younger plasma, only older plasma, and any older plasma groups) according to the storage time of the plasma (cutoff point, 323 days).

Results: After we had excluded 122 patients who were unavailable for follow-up, we found that 375 of the remaining patients $(n=745)$ received only younger plasma 370 patients received any older plasma, and 200 patients received only older plasma (mean follow-up, $1565 \pm 1137$ days; median follow-up, 1629 days). The storage time of plasma, when entered as either a continuous variable or a dichotomous variable, was a risk factor for early but not late mortality. Log-rank testing revealed no statistical difference in long-term survival among the groups.

Conclusions: Longer storage time of plasma is a risk factor for early but not late mortality among patients who have undergone coronary artery bypass grafting. (J Thorac Cardiovasc Surg 2011;141:238-43)

Supplemental material is available online.

Critically ill patients, including those who have undergone cardiac surgery, often have more severe complications if they have received a blood transfusion during the perioperative period. ${ }^{1,2}$ The storage time of red blood cells may influence the risk of such complications, ${ }^{3-8}$ because these cells undergo structural and functional changes that can reduce their function and viability after transfusion. ${ }^{8-10}$ Recently, some ${ }^{11}$ but not all ${ }^{12,13}$ authors have expressed concern about using older red blood cells for transfusion after cardiac

From the Departments of Cardiothoracic Surgery ${ }^{\mathrm{a}}$ and Education and Research ${ }^{\mathrm{b}}$ and the Clinical Laboratory, ${ }^{\mathrm{c}}$ Catharina Hospital, Eindhoven, The Netherlands; the Department of Anesthesiology, ${ }^{\mathrm{d}}$ The Feinberg School of Medicine, Northwestern University, Chicago, Ill; and the Department of Anesthesiology, ${ }^{\mathrm{e}}$ Catharina Hospital-Brabant Medical School, Eindhoven, The Netherlands and the University Hospital Ghent, Ghent, Belgium.

Disclosures: Authors have nothing to disclose with regard to commercial support.

Received for publication Oct 1, 2009; revisions received April 5, 2010; accepted for publication May 20, 2010; available ahead of print Sept 20, 2010.

Address for reprints: Mohamed A. Soliman Hamad, MD, Department of Cardiothoracic Surgery, Catharina Hospital, Michelangelolaan 2, Postbus 1350, 5602 ZA Eindhoven, The Netherlands (E-mail: aasmsn@cze.nl).

0022-5223/\$36.00

Copyright @ 2011 by The American Association for Thoracic Surgery doi:10.1016/j.jtcvs.2010.05.054 surgery. In their reports, several end points regarding heterogeneous patient populations have been mentioned.

The transfusion of fresh-frozen plasma (FFP) from female donors can lead to transfusion-related acute lung injury. ${ }^{14-19}$ To our knowledge, no data regarding the effect of the storage time of transfused FFP on early and late outcomes after coronary artery bypass grafting are available. We therefore studied whether the storage time of transfused FFP increases the risk for early or late mortality in a large group of patients who underwent coronary artery bypass grafting in a single center.

\section{MATERIALS AND METHODS Patients}

This study included the data from all adult patients who underwent isolated coronary artery bypass grafting in Catharina Hospital, Eindhoven, The Netherlands, between January 1998 and December 2007. Data collection was initiated in January 1998, when clinical information (demographic data, risk factors, and complications) for the study subjects was prospectively collected in a database.

\section{Study Design}

Approval was obtained from the institution's research review board. Data on blood transfusions and the storage time of FFP were collected from the database of the hospital transfusion service. All patients who had received at least 1 unit of FFP between the day of operation and the 5 th postoperative day were included in this study. Patients who had received more than 10 units of red blood cells were excluded from the analysis. The maximum time of storage of the transfused FFP per patient was 


\section{Abbreviation and Acronym \\ FFP $=$ fresh-frozen plasma}

referred to as the maximum storage time. The patients were divided into 3 groups according to the storage time of FFP: patients who received only FFP that had been stored for less than 323 days (the younger FFP group), patients who received only FFP that had been stored for at least 323 days (the only older FFP group), and patients who received a least 1 unit of older FFP (the any older FFP group). We used a cutoff point of 323 days because that was the median maximum storage time of all FFP transfused in this study. Patients in the only older FFP group were also included in the any older FFP group.

\section{Operative Technique}

All patients received short-acting anesthetic drugs to facilitate early extubation. Normothermic extracorporeal circulation was performed with nonpulsatile flow. Either cold crystalloid cardioplegia (St. Thomas solution) or warm blood cardioplegia, according to the surgeon's preference, was used to induce and maintain cardioplegic arrest. All patients who underwent coronary artery bypass grafting with the use of extracorporeal circulation received low-dose aprotinin (2 million kallikrein inactivation units) during extracorporeal circulation that was administered in the prime solution of the heart-lung machine, as was the usual practice in our hospital. Patients who underwent off-pump surgery did not receive aprotinin.

\section{Storage of FFP}

After withdrawal of the donor blood, the plasma was frozen and stored for at least 6 months at $-30^{\circ} \mathrm{C}$ before it was released for transfusion. During those 6 months, the donor was tested for viral diseases. The maximum allowed storage time is 2 years.

\section{Follow-up}

Follow-up data on the mortality of the patients studied were gathered from the databases of Dutch health insurance companies. Initially, the data for $9 \%$ of the total patient group could not be retrieved from those databases. We then contacted the general practitioners of those subjects to obtain the required mortality data. If necessary, we also contacted the authorities of the city in which those patients lived at the time of surgery. Postoperative mortality was defined as early ( $\leq 30$ days) or late ( $>30$ days).

\section{Indication for Transfusion of FFP}

The main indication for plasma transfusion in our center is excessive postoperative bleeding caused by coagulation disorder. FFP was given if 1 or more of the following laboratory tests yielded abnormal results: activated partial thromboplastin time, prothrombin time, international normalized ratio, and fibrinogen level. The choice to transfuse old or young FFP was made randomly, without any previously agreed protocol.

\section{Statistical Analyses}

Discrete variables were compared with the $\chi^{2}$ test and are presented as numbers and percentages of patients. Continuous variables were compared with the $t$ test and analysis of variance and are presented as the mean \pm SD. Univariate and multivariate logistic regression analyses were performed to investigate the impact of biomedical variables on early mortality. Multivariate analyses were used to test for the potentially confounding effects of biomedical and demographic factors on outcome. Cox proportional hazard regression analyses were performed for the same analyses of late mortality. If they were significant, confounders were included in multivariate logistic and Cox regression analyses.
Factors that were significant in the univariate analyses were entered into a multivariate model, together with the items of interest (the number of transfused FFP units and the maximum storage time per patient as a continuous variable and as a dichotomous variable). The following 3 factors were entered in 3 separate models, together with other variables: maximum storage time of FFP, only older FFP, and any older FFP. Long-term survival was described with the Kaplan-Meier method. A comparison of long-term survival was performed with log-rank statistics. The zero time point indicated the time of coronary artery bypass grafting. Odds ratios and hazard ratios with $95 \%$ confidence intervals are reported. All statistical analyses were performed with SPSS software (Statistical Product and Service Solutions, version 15.0; SSPS Inc, an IBM Company, Chicago, Ill).

\section{RESULTS}

During a 10-year period (January 1998-December 2007) 10,626 patients underwent coronary artery bypass grafting in our hospital. Excluded from the analysis were patients who were unavailable for follow-up $(\mathrm{n}=122)$ and those who received more than 10 units of red blood cells $(\mathrm{n}=80)$. Of the remaining patients, 375 received only younger FFP, 370 received any older FFP, and 200 patients received only older FFP. The mean follow-up was $1565 \pm$ 1137 days (range, $0-3704$ days), with follow-up considered 0 days in cases of operative death. The median follow-up was 1506 days, the mean storage time for FFP was $341 \pm$ 94 days (range, 196-730 days), and the median storage time for FFP was 323 days. The distribution of FFP storage times is shown in Figure E1.

Baseline characteristics stratified by storage time are shown in Table 1. None of the differences among the patient groups in baseline characteristics was significant except for re-exploration, which occurred more often among patients who had received only younger FFP, and the numbers of transfused units of FFP and platelets, which were higher among patients who had received any older FFP. Only the number of units of transfused platelets was higher in the group of patients who had received only older FFP.

Early mortality occurred more often among patients who received older FFP (ie, in $7.0 \%$ of those who received any older FFP and in $9.0 \%$ of those who received only older FFP) than in patients who received younger FFP $(3.2 \%)$, as shown in Table E1. Univariate logistic regression analyses (Table E2) revealed that the maximum storage time of FFP was a significant risk factor for early mortality, both as a continuous variable and as a dichotomous variable with a cutoff point of 323 days (only older FFP plasma and any older FFP versus younger FFP). Other risk factors for early mortality were age, chronic obstructive pulmonary disease, diabetes, low creatinine clearance, a left ventricular ejection fraction lower than $35 \%$, a low preoperative hemoglobin level, previous cardiac surgery, emergency operation, perioperative myocardial infarction, and the numbers of units of transfused red blood cells, FFP, and platelets. Univariate Cox regression analyses did not reveal the maximum storage time of FFP as a risk factor for late mortality. 
TABLE 1. Baseline characteristics stratified by storage age of fresh-frozen plasma transfused

\begin{tabular}{|c|c|c|c|c|c|}
\hline & $\begin{array}{c}\text { Younger FFP } \\
(\mathbf{N}=\mathbf{3 7 5}) \\
\end{array}$ & $\begin{array}{l}\text { Any older FFP } \\
(\mathbf{N}=\mathbf{3 7 0})\end{array}$ & $P$ value & $\begin{array}{l}\text { Only older FFP } \\
(\mathbf{N}=\mathbf{2 0 0})\end{array}$ & $P$ value \\
\hline \multicolumn{6}{|l|}{ Preoperative factors } \\
\hline Age $(y$, mean $\pm S D)$ & $65.0 \pm 9.4$ & $65.7 \pm 9.9$ & .288 & $66.4 \pm 9.3$ & .088 \\
\hline Male (no.) & $305(81.3 \%)$ & $307(83.0 \%)$ & .313 & $164(82.0 \%)$ & .470 \\
\hline Diabetes (no.) & $76(20.3 \%)$ & $69(18.6 \%)$ & .321 & $37(18.5 \%)$ & .348 \\
\hline Hypertension (no.) & $146(38.9 \%)$ & $134(36.2 \%)$ & .245 & $83(41.5 \%)$ & .305 \\
\hline Chronic obstructive pulmonary disease (no.) & $45(12.0 \%)$ & $50(13.5 \%)$ & .305 & $29(14.4 \%)$ & .234 \\
\hline Peripheral vascular disease (no.) & $48(12.8 \%)$ & $44(11.9 \%)$ & .396 & $28(14.0 \%)$ & .388 \\
\hline Left ventricular ejection fraction $<35 \%$ (no.) & $12(3.4 \%)$ & $18(5.3 \%)$ & .163 & $6(3.2 \%)$ & .560 \\
\hline Creatinine clearance $(\mathrm{mL} / \mathrm{min}$, mean $\pm \mathrm{SD})$ & $71.2 \pm 23.9$ & $70.5 \pm 23.9$ & 690 & $70.1 \pm 24.3$ & .606 \\
\hline Emergency (no.) & $46(12.3 \%)$ & $49(13.2 \%)$ & .386 & $29(14.5 \%)$ & .263 \\
\hline Preoperative hemoglobin $(\mathrm{g} / \mathrm{dL}$, mean $\pm \mathrm{SD})$ & $13.7 \pm 1.5$ & $13.8 \pm 1.4$ & .414 & $13.6 \pm 1.1$ & .494 \\
\hline Cardiac reoperation (no.) & $55(14.7 \%)$ & $52(14.1 \%)$ & .447 & $28(14.0 \%)$ & .467 \\
\hline \multicolumn{6}{|l|}{ Perioperative and postoperative factors } \\
\hline No of grafts (mean \pm SD) & $3.3 \pm 1.2$ & $3.4 \pm 1.1$ & .471 & $3.3 \pm 1.1$ & .708 \\
\hline Off pump (no.) & $26(6.9 \%)$ & $26(7.0 \%)$ & .537 & $18(9.0 \%)$ & .233 \\
\hline $\begin{array}{l}\text { Extracorporeal circulation time } \\
(\mathrm{min}, \text { mean } \pm \mathrm{SD})\end{array}$ & $66.2 \pm 44.0$ & $65.4 \pm 42.9$ & .798 & $65.2 \pm 45.6$ & .786 \\
\hline Intra-aortic balloon pump (no.) & $32(8.5 \%)$ & $30(8.1 \%)$ & .469 & $15(7.5 \%)$ & .398 \\
\hline Re-exploration (no.) & $134(35.7 \%)$ & $120(32.4 \%)$ & .191 & $50(25.0 \%)$ & .005 \\
\hline Perioperative myocardial infarction (no.) & $32(8.5 \%)$ & $28(7.6 \%)$ & .364 & $14(7.0 \%)$ & .318 \\
\hline Red blood cells (units, mean \pm SD) & $3.7 \pm 2.7$ & $3.8 \pm 2.8$ & .740 & $3.3 \pm 2.5$ & .066 \\
\hline FFP (units, mean \pm SD) & $2.5 \pm 1.1$ & $2.8 \pm 1.5$ & .001 & $2.4 \pm 1.1$ & .409 \\
\hline Platelets (units, mean \pm SD) & $0.29 \pm 0.56$ & $0.46 \pm 0.81$ & .001 & $0.42 \pm 0.75$ & .016 \\
\hline
\end{tabular}

Factors that were significant for late mortality were age, chronic obstructive pulmonary disease, diabetes, low creatinine clearance, low preoperative hemoglobin level, previous cardiac surgery, peripheral vascular disease, hypertension, perioperative myocardial infarction, and the numbers of units of transfused red blood cells and FFP. All risk factors that were identified in univariate analyses were entered into the multivariate logistic regression and multivariate Cox regression models (Table 2).

\section{Early Mortality}

The maximum storage time of FFP, when entered as a continuous and as a dichotomous variable with a cutoff point of 323 days (only older FFP and any older FFP versus younger FFP), was identified as an independent risk factor for early mortality. Because the numbers of red blood cell, FFP and platelet units were entered into the multivariate model, this effect was independent of the number of transfusion of blood products. The number of transfused platelet units was not significant as a predictor of early mortality. Other independent risk factors for early mortality were as follows: diabetes, a left ventricular ejection fraction less than $35 \%$, and perioperative myocardial infarction.

\section{Late Mortality}

The maximum storage time of FFP, when entered as either a continuous variable or a dichotomous variable with a cutoff point of 323 days (older versus younger FFP), was not identified as an independent risk factor for late mortality. Independent risk factors for late mortality were the number of transfused FFP units, age, chronic obstructive pulmonary disease, diabetes, low preoperative hemoglobin level, and perioperative myocardial infarction. The number of transfused platelet units was not significant in the univariate analysis for late mortality and therefore was not entered into the multivariate analysis.

Figure E1 shows the normal distribution of maximum storage time of FFP per patient. The predicted probability for early mortality increased with storage time for all patients, as well as for patients who received 1 or 2 units of FFP, as shown in Figures 1 and 2.

The survival curves of patients who received a transfusion only of younger FFP and those who received any older FFP are shown in Figure E2. The survival curves of those patients who received a transfusion of younger FFP and of those who received only older FFP are shown in Figure 3. The differences between the curves did not reach statistical significance. It is clear, however, that there is a distinct difference in the early postoperative period.

\section{DISCUSSION}

This retrospective study shows that the transfusion of older FFP is an independent risk factor for early but not late mortality. The study population consisted of patients 
TABLE 2. Multivariate logistic regression analyses for early mortality and Cox regression analyses for late mortality

\begin{tabular}{|c|c|c|c|c|c|c|}
\hline \multirow[b]{2}{*}{ Risk factor } & \multicolumn{3}{|c|}{ Early mortality } & \multicolumn{3}{|c|}{ Late mortality } \\
\hline & OR & $95 \% \mathrm{CI}$ & $P$ value & HR & $95 \% \mathrm{CI}$ & $P$ value \\
\hline FFP maximum storage time* & 1.004 & $1.001-1.008$ & .023 & 1.001 & $0.998-1.003$ & .622 \\
\hline Any older FFP & 2.29 & $1.00-5.22$ & .048 & 0.93 & $0.62-1.51$ & .104 \\
\hline Only older FFP & 3.43 & $1.32-8.92$ & .011 & 0.78 & $0.42-1.43$ & .159 \\
\hline Red blood cell units transfused* & 1.067 & $0.902-1.261$ & .451 & 0.931 & $0.852-1.016$ & .110 \\
\hline FFP units transfused* & 1.025 & $0.785-1.338$ & .856 & 1.347 & $1.165-1.558$ & $<.0001$ \\
\hline Platelet units transfused* & 1.406 & $0.847-2.332$ & .188 & & & \\
\hline Age* & 1.022 & $0.972-1.075$ & .401 & 1.048 & $1.016-1.081$ & .003 \\
\hline Chronic obstructive pulmonary disease & 1.83 & $0.72-1.07$ & .201 & 2.68 & $1.67-4.31$ & $<.0001$ \\
\hline Diabetes & 3.34 & $1.46-7.62$ & .004 & 1.75 & $1.10-2.79$ & .018 \\
\hline Creatinine clearance* & 0.995 & $0.974-1.016$ & .640 & 0.986 & $0.972-1.001$ & .064 \\
\hline Left ventricular ejection fraction $<35 \%$ & 3.65 & $1.08-12.29$ & .036 & & & \\
\hline Preoperative hemoglobin* & 0.837 & $0.649-1.079$ & .170 & 0.860 & $0.744-0.995$ & .043 \\
\hline Cardiac reoperation & 1.74 & $0.68-4.47$ & .244 & 1.57 & $0.95-2.61$ & .078 \\
\hline Peripheral vascular disease & & & & 1.40 & $0.81-2.42$ & .216 \\
\hline Emergency & 2.22 & $0.68-7.18$ & .183 & & & \\
\hline Perioperative myocardial infarction & 4.11 & $1.54-10.95$ & .005 & 3.62 & $2.00-6.56$ & $<.0001$ \\
\hline
\end{tabular}

$H R$, Hazard ratio; $C I$, confidence interval; $O R$, odds ratio; $F F P$, fresh-frozen plasma. *Entered as a continuous variable.

who received at least 1 unit of FFP and as many as 10 units of red blood cells intraoperatively or within the first 5 postoperative days after coronary artery bypass grafting. Patients who received more than 10 units of red blood cells were excluded from this study. The reason is that most of these patients had massive blood loss as a result of surgical calamities that caused various complications, including death. Thus the outcome in such cases was mainly influenced by the major surgical insult. The decision to transfuse younger or older FFP was random, according to the availability of the FFP. The cutoff point for younger and older FFP of 323 days (the median storage time) was arbitrary. In the multivariate logistic regression analyses, the maximum storage time used both as a continuous variable and as a dichotomous variable was revealed as an independent risk factor. The year of operation did not prove to be an independent risk factor for early mortality, and the storage protocol did not change with time. This indicates a real effect of storage age on early mortality. The predicted probability for early mortality increased with longer per patient maximum storage time. The same was found for patients who received 1 or 2 units of FFP. This confirms the results of the multivariate regression analyses, which showed the storage time to be an independent risk factor.

Although the late mortalities were less in the any older FFP group and the only older FFP group, multivariate analyses revealed that late mortality was not influenced by the storage time of FFP. Surprisingly, the numbers of units of transfused red blood cells, FFP, and platelets did not prove to be a risk factor for early mortality. This can be probably explained by the fact that in this subgroup of patients who received FFP, the mean number of transfused red blood cell units was already high (mean $3.6 \pm 2.6$ units). The trans- fusion of additional red blood cells in those patients did not increase the risk for mortality or morbidity any further.

In previous reports, transfusion-related acute lung injury has been described, ${ }^{14-19}$ The authors of those reports suggested that leukocyte antibodies and FFP from female donors might be important risk factors for the development of transfusion-related acute lung injury in critically ill patients. A recent report, ${ }^{20}$ however, did not support this finding.

To our knowledge, no data are available regarding the effect of the storage time of FFP on short-term and long-term outcomes after coronary artery bypass grafting. We found a clear relationship between the storage time of FFP and

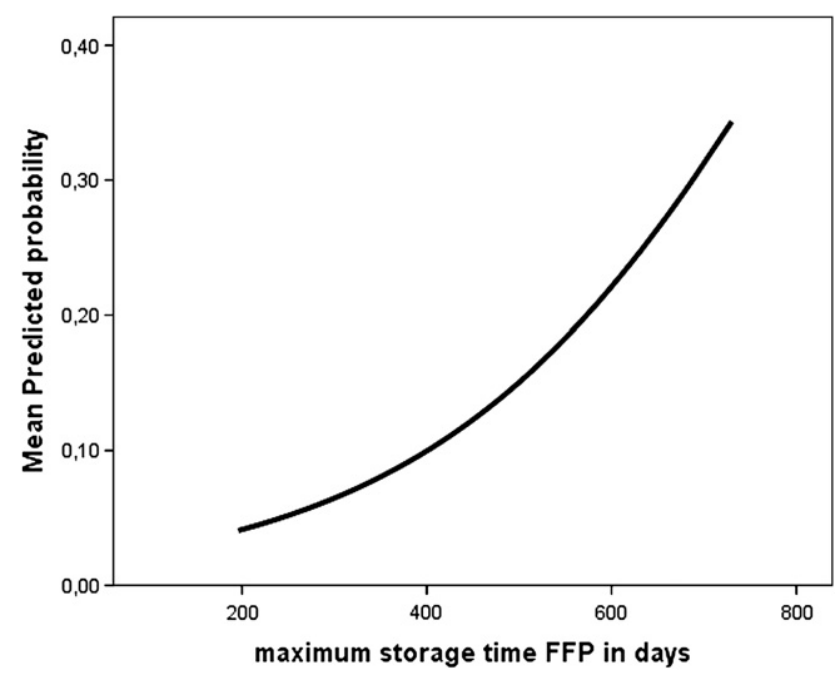

FIGURE 1. Predicted probability for early mortality for all patients. FFP, Fresh-frozen plasma. 


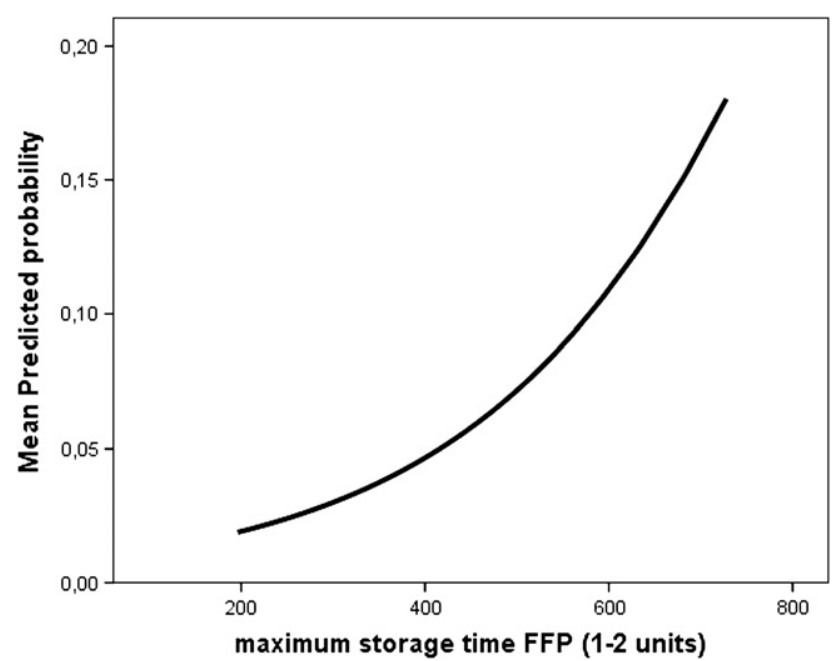

FIGURE 2. Predicted probability for early mortality for patients with 1 to 2 units of fresh-frozen plasma $(F F P)$.

early mortality. Baseline characteristics were similar between patients who received younger FFP and those who received older FFP. To further eliminate the effect of confounders, multivariate analyses were performed. The results of those analyses led to the conclusion that the transfusion of older FFP resulted in a poorer early outcome but that there was no relationship between the storage time of FFP and late outcome. The predicted probability for early mortality increased with longer per patient maximum FFP storage time. The same was found for patients who received 1 or 2 units of FFP. This confirms the results of the multivariate

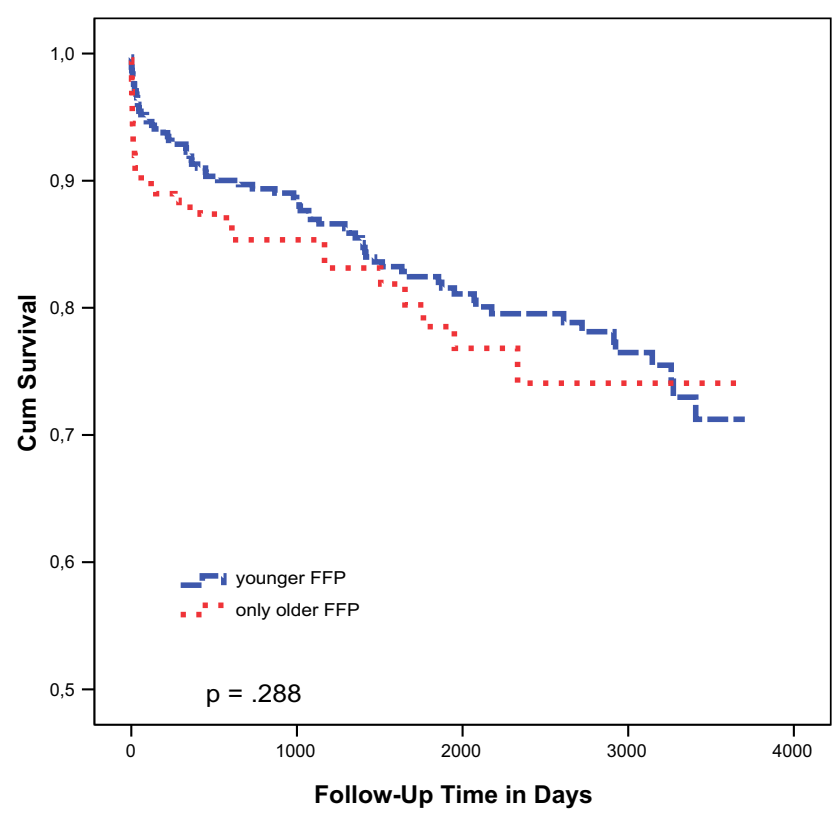

FIGURE 3. Kaplan-Meier curves for patients receiving younger or only older fresh-frozen plasma (FFP). Cum, Cumulative. regression analyses, which showed that the FFP storage time was an independent risk factor.

It has been demonstrated that prothrombin time and activated partial thromboplastin time are influenced by freezing and storage. This effect is more pronounced at $-20^{\circ} \mathrm{C}$ than at $-70^{\circ} \mathrm{C}^{21}$ Factor VIII levels are influenced by the storage temperature after thawing ${ }^{22,23}$ or after storage without freezing. ${ }^{24}$ It has also been shown that slow freezing causes a more pronounced decrease in the level of factor VIII than does more rapid freezing. ${ }^{25}$ In The Netherlands, blood products are stored at $-30^{\circ} \mathrm{C}$. At that temperature, the degeneration of clotting factors and other proteins cannot be excluded. Degeneration may lead to less effective clotting factors, and the degenerated proteins may produce unknown adverse effects. This possible progressive degeneration of proteins might be the reason that our subjects who received older FFP had relatively worse outcomes. Further studies are needed to investigate the possible progressive degeneration of proteins. Because most transfused FFP is older than 300 days, it might be advantageous to use younger FFP for transfusion whenever possible until that issue has been further clarified.

\section{Study Limitations}

In this retrospective study, factors not included in the list of demographic characteristics may explain the differences between the patient groups. A prospective, randomized trial should resolve that shortcoming. The primary end point of the study was all-cause mortality. Unfortunately, we were not able to retrieve the causes of death for these patients, data that are equally important. Moreover, the effects of storage time of FFP on postoperative complications such as sepsis or pulmonary complications remain unknown. Correlation between the storage time of FFP and postoperative bleeding and re-exploration was also not determined. This is another important shortcoming.

This investigation was a single-center study performed in The Netherlands. Whether our results can be applied to coronary artery bypass grafting performed in other countries in which different protocols for blood withdrawal, processing, and storage are practiced remains to be determined.

\section{CONCLUSIONS}

In a study of the 745 of 10,626 patients undergoing coronary artery bypass grafting who received FFP intraoperatively or within the first 5 postoperative days after coronary artery bypass grafting, we found that the longer storage time of FFP was an independent risk factor for early but not late mortality.

We thank the Sanquin Blood Supply Foundation in The Netherlands for help in collecting the data for this study. We also thank Professor A. Brand and Dr L. van de Watering for their support and advice in preparing the manuscript. 


\section{References}

1. Robinson WP III, Ahn J, Stiffler A, Rutherford EJ, Hurd H, Zarzaur BL, et al. Blood transfusion is an independent predictor of increased mortality in nonoperatively managed blunt hepatic and splenic injuries. J Trauma. 2005;58:437-45.

2. Malone DL, Dunne J, Tracy JK, Putnam AT, Scalea TM, Napolitano LM. Blood transfusion, independent of shock severity, is associated with worse outcome in trauma. J Trauma. 2003;54:898-907.

3. Koch CG, Li L, Duncan AI, Mihaljevic T, Cosgrove DM, Loop FD, et al. Morbidity and mortality risk associated with red blood cell and blood-component transfusion in isolated coronary artery bypass grafting. Crit Care Med. 2006; 34:1608-16.

4. Kuduvalli M, Oo AY, Newall N, Grayson AD, Jackson M, Desmond MJ, et al. Effect of peri-operative red blood cell transfusion on 30-day and 1-year mortality following coronary artery bypass surgery. Eur J Cardiothorac Surg. 2005;27: 592-8.

5. Engoren MC, Habib RH, Zacharias A, Schwann TA, Riordan CJ, Durham SJ. Effect of blood transfusion on long-term survival after cardiac operation. Ann Thorac Surg. 2002;74:1180-6.

6. Zallen G, Offner PJ, Moore EE, Blackwell J, Ciesla DJ, Gabriel J, et al. Age of transfused blood is an independent risk factor for post injury multiple organ failure. Am J Surg. 1999;178:570-2.

7. Purdy FR, Tweeddale MG, Merrick PM. Association of mortality with age of blood transfused in septic ICU patients. Can J Anaesth. 1997;44:1256-61.

8. Tinmouth A, Fergusson D, Yee IC, Hébert PC, ABLE Investigators, Canadian Critical Care Trials Group. Clinical consequences of red cell storage in the critically ill. Transfusion. 2006;46:2014-27.

9. Wolfe LC. Oxidative injuries to the red cell membrane during conventional blood preservation. Semin Hematol. 1989;26:307-12.

10. Berezina TL, Zaets SB, Morgan C, Spillert CR, Kamiyama M, Spolarics Z, et al. Influence of storage on red blood cell rheological properties. J Surg Res. 2002; 102:6-12.

11. Koch CG, Li L, Sessler DI, Figueroa P, Hoeltge GA, Mihaljevic T, Blackstone EH. Duration of red-cell storage and complications after cardiac surgery. N Engl J Med. 2008;358:1229-39.

12. Vamvakas EC, Carven JH. Length of storage of transfused red cells and postoperative morbidity in patients undergoing coronary artery bypass graft surgery. Transfusion. 2000;40:101-9.

13. van de Watering L, Lorinser J, Versteegh M, Westendord R, Brand A. Effects of storage time of red blood cell transfusions on the prognosis of coronary artery bypass graft patients. Transfusion. 2006;46:1712-8.
14. Chapman CE, Stainsby D, Jones H, Love E, Massey E, Win N, et al. Ten years of hemovigilance reports of transfusion-related acute lung injury in the United Kingdom and the impact of preferential use of male donor plasma. Transfusion. 2009;49:440-52.

15. Wiersum-Osselton JC, Porcelijn L, van Stein D, Vlaar AP, Beckers EA Schipperus MR. [Transfusion-related acute lung injury (TRALI) in the Netherlands in 2002-2005]. Ned Tijdschr Geneeskd. 2008;152:1784-8. Dutch.

16. Middelburg RA, van Stein D, Briët E, van der Bom JG. The role of donor antibodies in the pathogenesis of transfusion-related acute lung injury: a systematic review. Transfusion. 2008;48:2167-76.

17. Wright SE, Snowden CP, Athey SC, Leaver AA, Clarkson JM, Chapman CE, et al. Acute lung injury after ruptured abdominal aortic aneurysm repair: the effect of excluding donations from females from the production of fresh frozen plasma. Crit Care Med. 2008;36:1796-802.

18. Win N, Massey E, Lucas G, Sage D, Brown C, Green A, et al. Ninety-six suspected transfusion related acute lung injury cases: investigation findings and clinical outcome. Hematology. 2007;12:461-9.

19. Eder AF, Herron R, Strupp A, Dy B, Notari EP, Chambers LA, et al. Transfusionrelated acute lung injury surveillance (2003-2005) and the potential impact of the selective use of plasma from male donors in the American Red Cross. Transfusion. 2007;47:599-607.

20. Welsby IJ, Troughton M, Phillips-Bute B, Ramsey R, Lee Campbell M, Bandarenko N, Mathew JP, Stafford-Smith M; for members of Cardiothoracic Anesthesiology Research Endeavors. The relationship of plasma transfusion from female and male donors with outcome after cardiac surgery. J Thorac Cardiovasc Surg. doi:10.1016/j.jtcvs.2009.12.035

21. Alesci S, Borggrefe M, Dempfle CE. Effect of freezing method and storage at -20 degrees $\mathrm{C}$ and -70 degrees $\mathrm{C}$ on prothrombin time, aPTT and plasma fibrinogen levels. Thromb Res. 2009;124:121-6.

22. Buchta C, Felfernig M, Höcker P, Macher M, Körmöczi GF, Quehenberger P, et al. Stability of coagulation factors in thawed, solvent/detergent-treated plasma during storage at 4 degrees C for 6 days. Vox Sang. 2004;87:182-6.

23. Lamboo M, Poland DC, Eikenboom JC, Harvey MS, Groot E, Brand A, et al. Coagulation parameters of thawed fresh frozen plasma during storage at different temperatures. Transfus Med. 2007;17:182-6.

24. Smith JF, Ness PM, Moroff G, Luban NL. Retention of coagulation factors in plasma frozen after extended holding at 1-6 degrees C. Vox Sang. 2000;78 28-30.

25. Swärd-Nilsson AM, Persson PO, Johnson U, Lethagen S. Factors influencing factor VIII activity in frozen plasma. Vox Sang. 2006;90:33-9. 


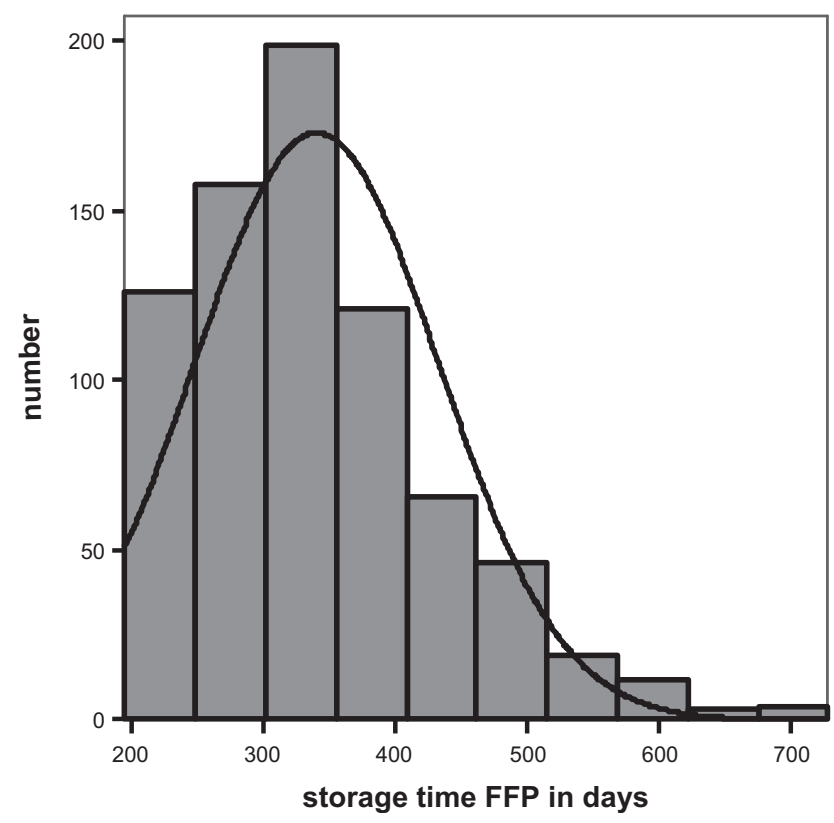

FIGURE E1. Distribution of maximum (per patient) storage time of freshfrozen plasma $(F F P)$.

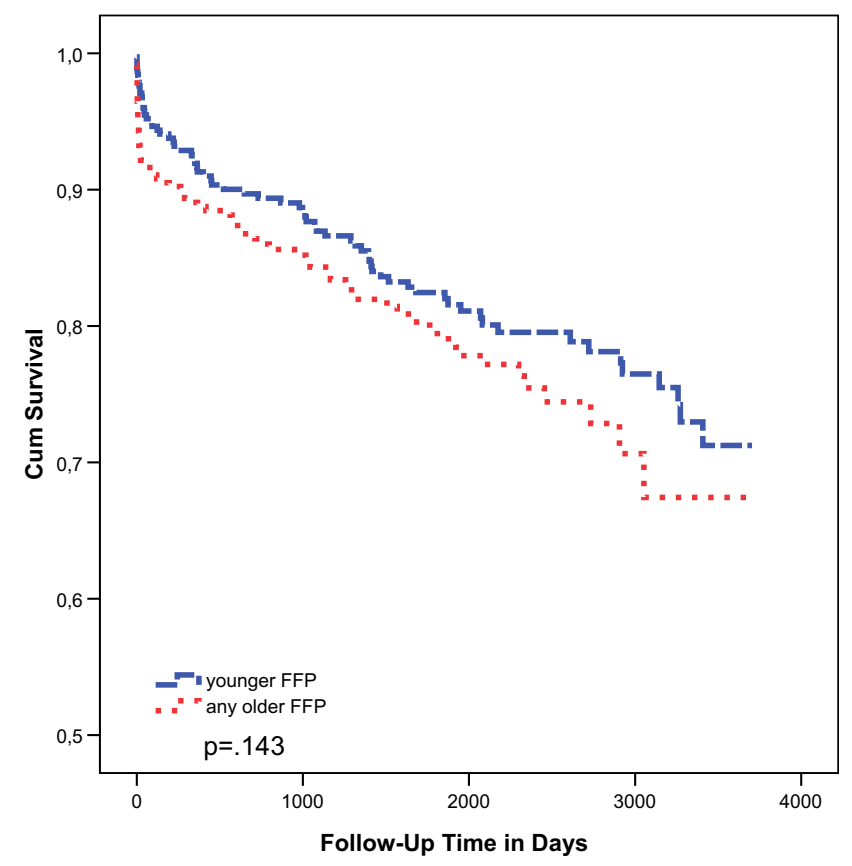

FIGURE E2. Kaplan -Meier curves for patients receiving only younger or any older fresh-frozen plasma $(F F P)$. 
TABLE E1. Early and late mortalities among patients receiving younger and older fresh-frozen plasma

\begin{tabular}{lcccc}
\hline & Younger FFP & Any older FFP & P value* & Only older FFP value* \\
\hline Early mortality (no.) & $12(3.2 \%)$ & $29(7.8 \%)$ & .004 & $18(9.0 \%)$ \\
Late mortality (no.) & $58(15.5 \%)$ & $43(11.6 \%)$ & .003 & $17(8.5 \%)$ \\
\hline
\end{tabular}

$F F P$, Fresh-frozen plasma. *Versus younger fresh-frozen plasma.

TABLE E2. Univariate logistic regression analyses of risk factors for early mortality and Cox regression analyses for late mortality

\begin{tabular}{|c|c|c|c|c|c|c|}
\hline \multirow[b]{2}{*}{ Risk factor } & \multicolumn{3}{|c|}{ Early mortality } & \multicolumn{3}{|c|}{ Late mortality } \\
\hline & OR & $95 \%$ CI & $P$ value & HR & $\mathbf{9 5} \% \mathrm{CI}$ & $P$ value \\
\hline \multicolumn{7}{|l|}{ Preoperative factors } \\
\hline Age* & 1.043 & $1.005-1.082$ & .027 & 1.077 & $1.051-1.104$ & $<.0001$ \\
\hline Male sex & 0.65 & $0.31-1.37$ & .264 & 0.72 & $0.45-1.14$ & .169 \\
\hline Chronic obstructive pulmonary disease & 2.34 & $1.11-4.96$ & .026 & 2.43 & $1.53-3.84$ & $<.0001$ \\
\hline Diabetes & 2.54 & $1.31-4.94$ & .006 & 1.97 & $1.28-3.04$ & .002 \\
\hline Creatinine clearance* & 0.977 & $0.961-0.992$ & .003 & 0.969 & $0.958-9.979$ & $<.0001$ \\
\hline Left ventricular ejection fraction $<35 \%$ & 4.20 & $1.50-11.73$ & .014 & 2.03 & $0.88-4.65$ & .093 \\
\hline Preoperative hemoglobin* & 0.702 & $0.577-0.855$ & $<.0001$ & 0.767 & $0.671-0.877$ & $<.0001$ \\
\hline Cardiac reoperation & 3.40 & $1.72-6.73$ & .001 & 1.78 & $1.11-2.86$ & .017 \\
\hline Peripheral vascular disease & 1.78 & $0.80-4.00$ & .120 & 2.21 & $1.35-3.61$ & .001 \\
\hline Emergency & 3.52 & $1.75-7.07$ & .001 & 1.54 & $0.89-2.66$ & .122 \\
\hline Hypertension & 1.18 & $0.62-2.25$ & .355 & 1.50 & $1.01-2.23$ & .045 \\
\hline \multicolumn{7}{|l|}{ Perioperative and postoperative factors } \\
\hline No. of grafts* & 0.825 & $0.634-1.074$ & .152 & 1.003 & $0.857-1.175$ & .970 \\
\hline Perioperative myocardial infarction & 3.04 & $1.33-6.91$ & .013 & 3.03 & $1.80-5.12$ & $<.0001$ \\
\hline Re-exploration & 0.79 & $0.39-1.57$ & .313 & 0.93 & $0.62-1.40$ & .745 \\
\hline Off pump & 1.47 & $0.50-4.31$ & .476 & 0.77 & $0.28-2.10$ & .616 \\
\hline Year of operation & 0.972 & $0.975-1.080$ & .596 & 0.961 & $0.879-1.052$ & .390 \\
\hline FFP maximum storage time* & $1 / 004$ & $1.001-1.007$ & .005 & 1.001 & $0.999-1.003$ & .294 \\
\hline Any older FFP & 2.57 & $1.29-5.12$ & .007 & 0.98 & $0.66-1.47$ & .943 \\
\hline Only older FFP & 2.99 & $1.41-6.34$ & .004 & 0.80 & $0.46-1.39$ & .439 \\
\hline FFP units transfused & 1.264 & $1.074-1.487$ & .005 & 1.239 & $1.096-1.400$ & .001 \\
\hline Platelet units transfused & 1.698 & $1.228-2.347$ & .001 & 1.183 & $0.893-1.566$ & .242 \\
\hline Red blood cell units transfused & 1.220 & $1.091-1.364$ & $<.0001$ & 1.089 & $1.016-1.168$ & .016 \\
\hline
\end{tabular}

$O R$, Odds ratio; $C I$, confidence interval; $H R$, hazard ratio; $F F P$, fresh-frozen plasma. *Entered as a continuous variable. 